\title{
A DEMOCRACIA DE CIDADÃOS PROPRIETÁRIOS E SUA RELAÇÃO COM OS PRINCÍPIOS DE JUSTIÇA COMO EQUIDADE DE JOHN RAWLS
}

\author{
Victor Augusto de Oliveira Meira ${ }^{1}$ \\ Victor Sales Pinheiro ${ }^{2}$
}

\section{RESUMO:}

O objetivo deste trabalho é analisar o papel do direito de propriedade na teoria de justiça de John Rawls a partir de sua ideia de democracia de cidadãos proprietários, em seu aspecto teórico e prático. Conclui-se que há uma forte conexão entre estes princípios de justiça e a democracia de cidadãos-proprietários, ressaltando-se a necessidade de maiores estudos a partir de contextos de desigualdade fundiária. A metodologia utilizada para o fim de alcançar os objetivos apresentados é a revisão bibliográfica das obras de John Rawls e a análise de artigos científicos que tratam da relação entre propriedade e justiça.

Palavras-chave: Justiça como Equidade; John Rawls; Democracia de Cidadãos Proprietários; Direito de Propriedade; Justiça.

\section{PROPERTY RIGHT AND ITS RELATIONSHIP WITH JOHN RAWL'S JUSTICE AS FAIRNESS PRINCIPLES: THE PROPERTY OWNING DEMOCRACY}

\begin{abstract}
:
The objective of this work is to analyze the role of property rights in John Rawls' theory of justice based on the idea of property owning democracy, in its theoretical and practical aspect. The conclusion is that there is a strong connection between Rawls' principles of justice and the basic structure of property owning democracy, emphasizing the need for further studies based on land inequality contexts. The methodology used to achieve the presented objectives is the bibliographical review of the works of John Rawls and the analysis of scientific articles that deal with the relationship between property and justice.
\end{abstract}

Keywords: Justice as Fairness; John Rawls; Property Owning Democracy; Right to Property; Justice.

\section{INTRODUÇÃO}

A propriedade esteve presente em todas as sociedades humanas organizadas, sendo um fator político e econômico (produtivo) comum na historiografia. No Brasil, a propriedade privada é um dos direitos fundamentais reconhecidos na Constituição Federal de 1988, em seu

\footnotetext{
${ }^{1}$ Mestrando em Direito, Políticas Públicas e Desenvolvimento Regional no Programa de Pós-Graduação em Direito do Centro Universitário do Pará (CESUPA). Pós Graduado em Direito Agroambiental pelo Centro Universitário do Pará (CESUPA). Advogado. victor_meira@ hotmail.com.

2 Doutor em Filosofia pela UERJ. Mestre em Filosofia pela PUC-RIO. Professor adjunto da Universidade Federal do Pará (UFPA) e do Centro Universitário do Pará (CESUPA). vvspinheiro@ yahoo.com.br.
} 
art. 170, II, tida como princípio basilar da ordem econômica nacional, conforme os ditames da justiça social.

Tal reconhecimento nada mais é do que a positivação de um bem primário, basilar na estrutura de qualquer sociedade humana, pois sua instrumentalidade de sujeição da natureza aos homens, permite com que estes satisfaçam suas necessidades materiais com maior previsibilidade, segurança e cooperação.

Mas, qual seria a melhor concepção de justiça para a justificação de tal direito? Qual regime socioeconômico seria adequado à esta concepção?

John Rawls sempre foi tido primordialmente como um teórico e filósofo político, cuja concepção de justiça apontaria naturalmente para um estado de bem estar social capitalista, dado que seu liberalismo igualitário funcionaria como um meio termo entre a igualdade (socialismo) e a liberdade (libertarianismo).

Para o autor americano, de matriz liberal e portanto, com foco na proteção de direitos individuais, um regime democrático deve aceitar a enorme diversidade de valores culturais e morais, respeitando este pluralismo na tomada de decisões. Portanto, sua concepção de justiça deve ser imparcial quanto às formas de se viver uma vida digna, não impondo-as aos cidadãos. A obra fundamental de Rawls, onde expõe com clareza seus conceitos é "Uma teoria da justiça", publicada em 1971.

Sá (2019, p. 250, apud Brito Filho, 2014, p. 35) destaca uma das principais características da concepção liberal de justiça em comparação com a visão da filosofia clássica, afirmando que "Rawls inverte a lógica Aristotélica, para mostrar que a concepção de bem, ainda que seja fruto da comunidade, não pode sobrepor-se à concepção do que é justo".

Nesse contexto, não cabe ao Estado optar por nenhum conceito de bem ou doutrina particular em detrimento de outros, mas garantir a efetividade dos princípios estabelecidos no contrato original (hipotético). O cidadão terá, assim, a certeza de que seus interesses poderão ser perseguidos nas condições que foram pré-estabelecidas, por sua própria vontade, em um situação de igualdade e liberdade.

Para Rawls as instituição também devem ser justas, de modo que a estrutura básica da sociedade passa a ser objeto da justiça, e assim também deve ser justo o modo como as principais instituições sociais distribuem os direitos e os deveres fundamentais e as vantagens provenientes da cooperação social (SÁ, 2019, p. 251). 
Rawls parte de um ideal de sociedade onde as pessoas estariam cobertas pelo "véu da ignorância”, ou seja, onde ao decidir os arranjos sociais as partes não saberiam como as várias alternativas irão afetar sua situação individual, assim buscariam a situação que melhor atenderia a todos indistintamente (RAWLS, 2003, p. 122).

Além disso, Rawls pressupõe que as pessoas são seres racionais e desinteressados, que embora não tenham informações suficientes a respeito de seus objetivos, possuem conhecimento suficiente para fazer opções conscientes (SÁ, 2019, p. 253).

Com base nessas ideias Rawls formulará seus dois princípios de justiça, os quais seriam o critério para avalizar uma sociedade justa e que buscariam uma sociedade onde a desigualdade pudesse estabelecer o máximo benefício possível para os mais pobres.

Contudo, o próprio Rawls considerou (em obras posteriores, de sua vasta bibliografia) sua teoria da justiça inconsistente com os arranjos institucionais característicos do capitalismo do estado de bem-estar.

Em "Justice as Fairness" (Justiça como Equidade, publicado originalmente em 1985), Rawls reformulou sua teoria da justiça, defendendo formas e instrumentos mais radicais de organização socioeconômica, tais como a "democracia do cidadão proprietário" (Property Owning Democracy), que seria sua alternativa ao estado de bem-estar.

Esta proposta envolve uma forma de estruturar a propriedade e o controle dos meios de produção dentro da economia de forma prévia (ex ante), sendo uma aplicação direta dos princípios da justiça liberal igualitária, completamente diferente daquele encontrado em estados de bem-estar capitalistas, onde a distribuição da riqueza acontece posteriormente (ex post), através de mecanismos de tributação e assistencialismo (RAWLS, 2003, p.198).

A crítica principal de Rawls é referente ao fato de que no capitalismo de bem-estar, mesmo que haja alguma preocupação com a igualdade de oportunidade, as políticas necessárias para alcançá-la não são seguidas e há desigualdades muito grandes na propriedade (meios de produção e recursos naturais), de sorte que o controle da economia e da vida política ficam nas mãos de uma minoria. Não há reciprocidade (ALARCON, 2017, p. 31).

Rawls (2003, p.195), ao defender o regime socioeconômico da democracia de cidadãos proprietários como aquele amais adequado com seus princípios de justiça, afirma que este "garante as liberdades básicas juntamente com o valor equitativo das liberdades políticas e a igualdade de oportunidades, e regula as desigualdades econômicas e sociais por um princípio de mutualidade, se não pelo princípio da diferença”. 
Uma importante ressalva que se faz necessária é que, diferentemente do que se poderia pensar em princípio, a democracia de cidadãos-proprietários não implica a coletivização da propriedade privada dos meios de produção, mas traz consequências para a estrutura básica da sociedade e para as instituições de fundo, dispersando a propriedade de riqueza e capital e impedindo, dessa forma, que uma pequena parte da sociedade possa controlar a economia e também, indiretamente, a vida política (RAWLS, 2003, p. 198).

Para desenvolver o tema de maneira direta e gradativa se dividiu este trabalho em dois capítulos. Em um primeiro momento se inicia a abordagem do tema trazendo os conceitos necessários para o entendimento da concepção de Rawls acerca da justiça, desenvolvida em "Uma teoria da justiça", tais como posição original, véu da ignorância, bens primários, racionalidade e os princípios basilares da justiça como equidade.

Em um segundo momento, aborda-se o direito de propriedade sob a égide da concepção de justiça de John Rawls em seu aspecto teórico, relativo a sua classificação como direito fundamental, bem como de sua aplicação prática, que Rawls desenvolve na obra "Justiça como equidade" ao propor a tese de que seus princípios estão melhor articulados em um regime socioeconômico denominado "democracia de cidadãos proprietários".

A finalidade deste trabalho é demonstrar a importância deste elemento surpreendente e aparentemente radical da teoria de Rawls o qual não tem tanta atenção quanto ao aspecto teoria de sua teoria de justiça. Destarte, há uma necessidade de entender melhor a consequência prática da teoria da justiça como equidade e a natureza das propostas éticas, jurídicas, econômicas e institucionais, avaliando-se sua solidez e possibilidade real.

A metodologia utilizada para o fim de alcançar os objetivos apresentados é a revisão bibliográfica e comparativa entre as obras primeiras e posteriores de John Rawls, bem como a análise de artigos científicos que tratam do tema da propriedade e sua relação com a justiça.

\section{A CONCEPÇÃO DE JUSTIÇA LIBERAL IGUALITÁRIA EM JOHN RAWLS}

Em razão de uma miríade de opiniões e argumentações valorativas que impedem um consenso moral em uma sociedade politicamente diversa é que um filósofo político como John Rawls sentirá a necessidade de desenvolver uma concepção de justiça que abarque diversas possibilidades de planos racionais de vida, observando as diferenças e oportunidades, conforme o nível cultural, social e econômico dos indivíduos que a compõe. 
Em sua clássica obra "Uma Teoria da Justiça", publicada originalmente em 1971, Rawls procurou apresentar uma concepção de justiça liberal mas sem abandonar a ideia de igualdade, em oposição ao utilitarismo clássico, cujo princípio norteador seria o de maximização da utilidade das ações.

Essa concepção de justiça rawlsiana teria como objetivo oferecer critérios para um pensamento moral que baseasse uma sociedade fundada em um sistema equitativo de cooperação, onde os benefícios e encargos desta seriam distribuídos de forma justa (RAWLS, 2008, p.04-05).

[...] para Rawls faz sentido fazer uma avaliação sobre a justiça ou a injustiça das instituições básicas de nossa sociedade: a natureza não é justa ou injusta conosco, o que é justo ou injusto é o modo como o sistema institucional processa esses fatos da natureza. Daí surge sua afirmação de que a 'primeira virtude' de qualquer sistema institucional tem que ser a de sua justiça (GARGARELLA, 2008, p. 28).

Destarte, esta concepção de justiça diferencia fatos circunstanciais e fatos de responsabilidade dos indivíduos e será formada por princípios que governam a estrutura básica da sociedade, as instituições que formam seu núcleo constitutivo e tais princípios orientam a aplicação prática da justiça de modo mais direto e preciso.

Iremos desenvolver o tema, analisando os princípios de justiça rawlsianos, com o fito de articulá-los posteriormente com sua ideia de democracia dos cidadãos proprietários, procurando verificar aspectos mais práticos de sua teoria.

\subsection{Os princípios de justiça liberal igualitária}

Em razão de uma miríade de opiniões e argumentações valorativas que impedem um consenso moral em uma sociedade politicamente diversa é que um filósofo político como John Rawls sentirá a necessidade de desenvolver uma concepção de justiça que abarque diversas possibilidades de planos racionais de vida, observando as diferenças e oportunidades, conforme o nível cultural, social e econômico dos indivíduos que a compõe.

Em sua clássica obra "Uma Teoria da Justiça", publicada originalmente em 1971, Rawls procurou apresentar uma concepção de justiça liberal mas sem abandonar a ideia de igualdade, em oposição ao utilitarismo clássico, cujo princípio norteador seria o de maximização da utilidade das ações. 
Essa concepção de justiça rawlsiana teria como objetivo oferecer critérios para um pensamento moral que baseasse uma sociedade fundada em um sistema equitativo de cooperação, onde os benefícios e encargos desta seriam distribuídos de forma justa (RAWLS, 2008, p.04-05).

[...] para Rawls faz sentido fazer uma avaliação sobre a justiça ou a injustiça das instituições básicas de nossa sociedade: a natureza não é justa ou injusta conosco, o que é justo ou injusto é o modo como o sistema institucional processa esses fatos da natureza. Daí surge sua afirmação de que a 'primeira virtude' de qualquer sistema institucional tem que ser a de sua justiça (GARGARELLA, 2008, p. 28).

Destarte, esta concepção de justiça diferencia fatos circunstanciais e fatos de responsabilidade dos indivíduos e será formada por princípios que governam a estrutura básica da sociedade, as instituições que formam seu núcleo constitutivo e tais princípios orientam a aplicação prática da justiça de modo mais direto e preciso.

Rawls formula, então, dois princípios de justiça, sendo que o primeiro (liberdade igual) prevê que se deve assegurar aos indivíduos o mais amplo sistema possível de liberdades iguais, isto é, um rol de direitos básicos cuja inviolabilidade tem prioridade sobre qualquer outra consideração de justiça, inclusive sobre as condições de igualdade e direitos sociais previstas no segundo princípio.

É importante observar, contudo, que Rawls "não está endossando um princípio geral de liberdade de tal modo que qualquer coisa que possa ser plausivelmente chamada de liberdade deva receber prioridade avassaladora" (KYMLICKA, 2006, p.68). O que está sendo tratado são as liberdades básicas, direitos civis e políticos "padrão" em democracias liberais, como por exemplo o direito ao voto, o devido processo legal, o livre discurso, entre outros.

Já o segundo princípio (Diferença) prevê duas condições para que sejam aceitáveis diferenças sociais e econômicas entre os indivíduos: que resultem de cargos e posições abertas a todos e que coloquem os menos favorecidos em posição melhor do que estariam de outra forma. Se aplica, portanto, à distribuição de renda e riqueza e à estruturação de organizações que fazem uso de diferenças de autoridade e responsabilidades, tais como empresas e governos por exemplo (RAWLS, 2008, p.73-74). 
A base do contrato deve, segundo Rawls (2008, p. 240) estar de acordo com as convicções sociais mais sólidas ou mais enraizadas na cultura política pública de um regime constitucional e, progressivamente, os cidadãos poderão visualizar nas instituições sociais uma forma de atingir seus interesses que ficarão mais específicos conforme os estágios de aplicação dos princípios de justiça (procedimental). Reconhece-se, portanto, que há um objetivo prático à teoria da justiça como equidade.

\subsection{Posição original e véu da ignorância}

Para garantir que o acordo resultante da observação destes princípios sejam determinados de maneira equitativa, Rawls propõe a ideia da posição original: uma situação hipotética (experimento ideal) na qual todos os contratantes estariam em iguais condições ao escolherem os princípios básicos do acordo, o fazem da melhor forma possível para que todos possam atender seus interesses. E esta situação de absoluta igualdade seria garantida pelo que Rawls chama de véu da ignorância.

O véu de ignorância é uma condição epistemológica. Em linhas gerais, é uma condição para uma escolha imparcial e, na visão liberal de Rawls, justa. Nessa condição, as partes necessitam realizar uma avaliação sobre quais princípios de justiça escolher apenas com base em ponderações gerais, mas sem conhecimento de questões contingentes e pessoais. Dessa forma, haverá um referencial geral, mas não particular (GARGARELLA,2008 p. 21).

Como dito, o véu de ignorância não permite, por presunção, que as partes na posição original conheçam fatos específicos sobre elas próprias, tais como o seu lugar na sociedade, a própria sorte na distribuição dos dotes e das capacidades naturais, sua inteligência e força, a própria concepção de bem, as particularidades de seu projeto racional de vida e mesmo as características especiais de sua psicologia, como aversão ao risco, tendência ao otimismo ou pessimismo (RAWLS, 2008, p.166).

Ademais, os indivíduos nessa posição tampouco nada conheceriam acerca da própria sociedade em que estão inseridos, como a posição econômica ou política, o nível de civilização e cultura, a qual geração elas pertencem e as contingências que as colocam em oposição.

Estes indivíduos somente teriam conhecimento sobre os fatos gerais da sociedade humana referentes aos assuntos políticos, os princípios da teoria econômica, as bases da 
organização social e as leis da psicologia humana, bem como circunstancias de justiça que permitam com que as escolhas na posição original sejam justas, através da deliberação e cooperação humana (RAWLS, 2008, p. 167).

Não obstante os interesses e necessidades de tais sujeitos sejam semelhantes ou complementares, tornado a cooperação social mutuamente vantajosa, há diversos fatores subjetivos que tornam os indivíduos demasiado diferentes (o que faz parte da condição humana) e que, caso fossem conhecidos pelos indivíduos, poderiam distorcer o processo de escolha através da parcialidade, resultando em princípios de justiça “injustos".

Diferentes projetos de vida ou concepções diversas do bem fazem com que hajam reivindicações conflitantes quanto aos recursos disponíveis, limitações de juízo causadas por preconceitos e egoísmo, diversidade de convicções religiosas e filosóficas e de doutrinas políticas e sociais possíveis de serem atingidas pelo intelecto humano, são elementos que podem dificultar a escolha dos princípios basilares de justiça em uma sociedade democrática.

Por conta de tais dificuldades é que Rawls tentará neutralizar os elementos que impediriam esse acordo inicial, retirando dos indivíduos na posição original as informações sobre suas posições sociais e convicções pessoais, com o objetivo de fazê-los adotar um ponto de vista imparcial, sob a ótica de quem pudesse estar em qualquer posição social e ter qualquer convicção substantiva e, portando, defenderiam ao máximo uma posição intermediária na distribuição de bens e oportunidades, protegendo-se contra a possibilidade de que o regime distributivo que escolhessem as privasse dos bens mais indispensáveis para a persecução de quaisquer concepções de bem e projetos de vida (KYMLICKA, 2006, p.82).

Para estabelecer limites mínimos acerca do que poderá ser efetivamente escolhido na posição moral, a título de escolha justa, racional e definir os a forma de acepção aos bens primários, Rawls procurou restringir formalmente o conceito de justo. Nesse sentido, a ideia é definir as concepções de justiça que podem ser consideradas, pelas partes, na posição original como as mais razoáveis.

É a separação em lista de quais princípios poderão ser escolhidos, com base em critérios formais, que garantam que os princípios serão justos, ao final. Nesse sentido, características como generalidade, universalidade, publicidade, ordenação e finalidade são essenciais para a concepção do justo que se deseja atingir (RAWLS, 2008, p. 164). 
E como os indivíduos chegaram necessariamente a tais condições? Que tipo de racionalidade lhes é exigida?

\subsection{A racionalidade do indivíduo na Posição Original}

Para Rawls (2008, p. 174), os indivíduos em sociedade são dotados de uma racionalidade padrão, isto é, a capacidade de ter uma concepção de bem (isto é, do que é bom para si) e persegui-la fazendo as escolhas e empregando os meios adequados.

Munidos somente desta racionalidade, os indivíduos estão em situação de incerteza na posição original e, portanto, precisam de uma regra ou critério de escolha para encontrar os princípios mais justos de ordenação básica da sociedade.

Visando impedir um sistema baseado em utilidade, Rawls (2008, p. 183) afirma que as partes da posição original elegeriam a situação dos menos favorecidos como o ponto a ser observado no julgamento sobre a disparidade das diferenças e a comparação de sua situação em cenários alternativos de diferença como o critério para julgar se estas são aceitáveis.

Essa é a regra maximin (maximização do mínimo) onde, entre várias alternativas, observa-se o pior resultado possível de cada uma delas, e decide-se pela alternativa na qual este "pior resultado possível" seja o melhor. Ou seja, as partes decidem que o arranjo social mais desejado é aquele no qual os "menos afortunados" obtenham a maior quantidade de benefícios possíveis (GARGARELLA, 2008, p. 23-24).

Portanto, para Rawls os princípios de justiça fornecem a possibilidade de contornar a incerteza gerada pela posição original, uma vez que protegem, desde o início, as liberdades fundamentais e garantem a fruição das oportunidades sociais de maneira equiparável a todos os membros da comunidade. O véu da ignorância favorecerá os dois princípios de justiça em detrimento do princípio da utilidade média, sendo esta concepção de justiça mais adequada à situação de ignorância completa (RAWLS, 2008, p. 235), possibilitando uma concepção dos bens básicos que serão divididos.

Nesse contexto, insere-se questão amplamente debatida, raiz de problemas filosóficos e econômicos, qual seja, o direito de propriedade. Tal conceito está diretamente ligado a ideia de bens, liberdade, igualdade e, consequente, justiça e será discutido por Rawls. 


\section{O DIREITO DE PROPRIEDADE SOB À ÓTICA DA JUSTIÇA LIBERAL IGUALITÁRIA: ASPECTOS TEÓRICOS E PRÁTICOS}

No presente tópico, analisaremos primeiramente os fundamentos teóricos do direito de propriedade sob a ótica da justiça liberal igualitária de John Rawls, alguns apontamentos sobre base ética, moral e psicológica que sua teoria desenvolve para justificar a ideia de direito de propriedade como um direito fundamental dos seres humanos (propriedade como bem primário).

Em seguida, veremos como seria a aplicação prática dos princípios da concepção liberal igualitária de justiça, em um sistema econômico que tenha o direito de propriedade como fundamental e base de sua economia, através da ideia de democracia de cidadãos proprietários.

3.1. A propriedade como direito fundamental na concepção política de Rawls

O Direito de propriedade está diretamente presente em lista de direitos fundamentais enumerados no primeiro princípio de justiça de Rawls, relacionados às liberdades fundamentais que devem ser garantidas aos indivíduos: "entre as liberdades fundamentais da pessoa, está o direito à propriedade pessoal" (RAWLS, 2008, p. 74).

Segundo Weber, (2016, p. 811), o intuito do direito de propriedade seria o de "proporcionar uma base material suficiente para a independência da pessoa e um sentimento de autorrespeito, ambos essenciais para o desenvolvimento e exercício adequados das faculdades morais".

Sobre o autorrespeito, é necessário destacar que a concepção do bem como racionalidade nos leva a ter um plano racional de vida que considere o princípio aristotélico (desejo de realizar um padrão mais amplo de fins, que trazem à tona os talentos mais aprimorados. A busca pela excelência) e também nos leva a julgar nossos atos e com base na aceitação e confirmação de outros indivíduos pelos quais demonstramos admiração e manifestamos desejo de associação.

Ademais, os laços associativos fortalecem a autoestima na medida e que sendo variadas as capacidades, as habilidades e as comunidades de pessoas diversificadas, haverá:

Para cada pessoa pelo menos uma comunidade de interesses mútuos à qual ela pertença e onde veja seus esforços confirmados pelos 
associados [isso servirá de garantia para que] na vida pública os cidadãos respeitem os fins uns dos outros e julguem suas reivindicações políticas de maneira que também reforcem sua autoestima. É precisamente essa condição fundamental que é mantida pelos princípios de justiça (RAWLS, 2008, p. 546).

Segundo Rawls, sem o autorrespeito "todos os desejos e todas as atividades se tornam vazios e fúteis, e naufragamos na apatia e no ceticismo" (RAWLS, 2008, p.544)

Desta forma, a base ética, moral e psicológica subentendida em sua teoria justifica a propriedade como um direito fundamental, eis que servirá para suprir necessidades básicas dos cidadãos. A concretização do autorrespeito pela propriedade implica no desenvolvimento de um senso de justiça e uma concepção de bem, de forma que este é entendido como um bem primário (WEBER, 2016, p. 811).

É importante ressaltar que o conceito de propriedade para Rawls não deriva de nenhuma doutrina moral abrangente, pois a "autossustentabilidade" implica em reconhecer que não se pode recorrer a valores éticos ou religiosos para justificar os direitos fundamentais. Isto se diz em razão da impossibilidade de acordo quanto a este tipo de valor, que somente seria possível quanto aos valores políticos. É o caso do direito de propriedade, ou o que Rawls chama de "direito à propriedade pessoal" em "Uma Teoria da Justiça".

A sua justificação como valor político é a condição de possibilidade de um acordo como elemento constitucional essencial: efetiva possibilidade de sua proteção. Trata-se de concepção política de justiça, pois "elaborada para um tipo específico de objetivo, qual seja, para instituições políticas, sociais e econômicas" (RAWLS apud WEBER, 2016, p. 811), que representam a estrutura básica da sociedade.

Dessa forma, o direito de propriedade é uma espécie de "carro chefe" dos direitos fundamentais e representa a possibilidade de exercício pleno da cidadania. Sem sua efetivação, falta a base para satisfação das necessidades básicas dos cidadãos, sendo um componente indispensável do conteúdo do mínimo existencial. Este é o significado da referência a um "princípio lexicamente anterior" ao primeiro princípio de justiça (liberdade igual), que prevalece sobre o segundo, da diferença (WEBER, 2016, p. 814).

A propriedade como direito fundamental é incluída por Rawls na relação de bens primários, enfatizando ainda mais sua importância na ideia de justiça como equidade, pois esses bens são aquilo que, à luz da concepção política de justiça, as pessoas livres e iguais 
precisam como cidadãos cooperativos. Desta forma, a propriedade seria uma necessidade para os cidadãos terem dignidade e capacidade de cooperar em sociedade (WEBER, 2016, p. 812).

Pode-se afirmar que, na concepção de Rawls, a propriedade privada individual é um bem primário, sendo protegida por instituições sociais básicas e fundamentais para a ordem, tais como a Constituição e o Código Civil), sendo considerado uma liberdade fundamental deve ser protegido pelo fato de ser inerente à escolha dos indivíduos e está protegido pelos princípios de justiça, em especial o primeiro. Isso justifica, do ponto de vista teórico, que o direito de propriedade merece ser protegido enquanto direito fundamental, pelo simples fato de ser algo inerente à liberdade de escolha dos indivíduos (SÁ, 2019, p.261).

Em síntese, o desenvolvimento da concepção normativa de pessoa e o exercício pleno da cidadania requer o direito de propriedade assegurado.

No entanto, nenhuma das liberdades básicas é absoluta e isso inclui o direito à propriedade. Uma concepção de justiça não pode priorizar tipos de liberdades e permitir a perda de uns pelo bem maior de outros.

Ao versar sobre as liberdades fundamentais, as quais devem ser iguais a todos, Rawls exclui de seu rol certos tipos de propriedade (como o direito à herança ou a propriedade dos meios de produção), por entender que não são fundamentais e portanto não estão protegidos pela prioridade do primeiro princípio. (SÁ, 2019, p.255).

Esses dois aspectos do direito de propriedade não são indispensáveis para a realização das qualidades morais das pessoas, ou seja, da concepção política de pessoa. Afirma-se tal exclusão diante da controvérsia e impossibilidade de acordo político, o que os exclui da condição de bem primário, podendo vir a serem contemplados em estágios posteriores do desenvolvimento de direitos (estágio legislativo ${ }^{3}$ ) observando-se as circunstâncias específicas e aspectos históricos particulares de uma determinada sociedade (WEBER, 2016, p. 812).

Para Rawls, a igualdade de oportunidades significa dizer que aqueles que têm capacidades e habilidades similares devem ter oportunidades similares de vida, ou seja, que as posições das carreiras abertas aos talentos não estejam acessíveis apenas no sentido formal, mas também no sentido real e efetivo (SÁ, 2019, p.256). Veja-se, portanto, que não implica necessariamente em uma igualdade absoluta na distribuição de bens, mas de oportunidades.

\footnotetext{
${ }^{3}$ Dentro da sequência de quatro estágios, cuja ideia fora desenvolvida no Capítulo IV, item 39, de "Uma teoria da justiça" (RAWLS, 2008, p. 239).
} 
Ao mesmo tempo em que Rawls afirma que a desigualdade não pode ser tamanha que prejudique os mais pobres, também afirmará que a igualdade não pode prejudicar os direitos de propriedade e liberdade individuais, isto porque para este autor os princípios estão dispostos em ordem lexical (de prioridade), então mesmo as maiores vantagens sociais e econômicas não justificam a violação nem a limitação das liberdades fundamentais (SÁ, 2019, p.257).

Desta forma, como seria a aplicação prática dos princípios da concepção liberal igualitária de justiça, em um sistema econômico que tenha o direito de propriedade como fundamental e base de sua economia? Ele teria prioridade em um sistema econômico que permita uma distribuição equitativa da propriedade? É o que se pretende responder no próximo tópico, tratando do conceito de democracia do cidadão proprietário.

3.2. O sistema da democracia de cidadãos proprietários e sua compatibilidade com a teoria da justiça liberal igualitária

John Rawls também pensou nos aspecto prático da aplicação de sua concepção de justiça igualitária, ainda que de forma ideal e teórica. Através das ideias do economista James Edward Meade, de quem emprestou conceitos e terminologias, Rawls concebeu um sistema socioeconômico que poderia servir como alternativa ao capitalismo e adequado à promoção dos seus princípios de justiça (ALARCON, 2017, p. 43).

A democracia de cidadãos-proprietários, como ideia econômica, atua de duas formas: tributação e redistribuição de renda e riquezas.

No primeiro campo, não há nada de muito diverso das propostas tradicionais associadas ao "welfare state", com a característica especifica de que Meade defendia a tributação forte da transmissão de riqueza entre gerações e inter vivos, equiparando-as, bem como um aumento do gasto público com educação e desenvolvimento de capital humano (O’NEILL, 2009, p. 381).

Já no campo da redistribuição de riqueza, o foco principal não é o compartilhamento e redistribuição de capital, mas a dispersão da propriedade e do controle dos recursos produtivos estimulando a acumulação de pequenas propriedades, sendo uma característica marcante da proposta o foco na distribuição de riquezas e não somente renda, bem como o desestimulo a acumulação de propriedades familiares entre gerações. 
Meade tinha uma ideia de unificação política e forte integração nacional e um alto grau de dirigismo estatal. Rawls não se apropriou desta parte de suas ideias, mas focou principalmente na dimensão democrática do modelo econômico proposto por Meade, com o fito de construir um sistema social que contornasse as falhas dos regimes capitalistas de bem estar social, permitisse a aplicação de seus dois princípios de justiça e enfatizasse os valores políticos da liberdade, da igualdade e da democracia.

Segundo Alarcon (2017, p. 42) Rawls afirma que este sistema atende todos os desdobramentos dos princípios de justiça, pois seria capaz de assegurar as liberdades básicas, o valor equitativo das liberdades políticas, garantir uma igualdade equitativa de oportunidades, além de regular as desigualdades econômicas e sociais ex ante, através do princípio da diferença.

A democracia de cidadãos-proprietários se assemelha ao estado de bem estar social ao assegurar a propriedade privada dos meios de produção (não se trata de proposta socialista) mas sua estrutura se diferencia deste ao propor a dispersão da propriedade de riquezas e evitando um controle político por parte de uma minoria. Sendo a propriedade uma forma jurídica de representar o controle do poder político através dos recursos produtivos (econômicos), a proposta tem forte característica democrática, pois se vale também da dispersão do capital humano e dos poderes políticos entre cidadãos que são livres e iguais. Segundo o próprio Rawls (2003, p.197):

The intent is not simply to assist those who lose out through accident or misfortune (although that must be done), but rather to put all citizens in a position to manage their own affairs on a footing of a suitable degree of social and economic equality ${ }^{4}$.

Importante observar que isso ocorreria através de mecanismos redistributivos "ex ante", em oposição aos mecanismos do capitalismo de bem-estar social, que são "ex post", tal como é característico da proposta política de Rawls, exposta na primeira parte deste trabalho.

O’Neill (2009, p.382) resume bem as características gerais da proposta políticoeconômica da democracia de cidadãos proprietários sob a perspectiva da teoria de justiça liberal igualitária de Rawls, destacando três questões centrais: a dispersão de capital

\footnotetext{
${ }^{4}$ A intenção não é simplesmente ajudar aqueles prejudicados por acidente ou infortúnio (embora isso deva ser feito), mas sim colocar todos os cidadãos em condição de administrar seus próprios assuntos, em um nível adequado de igualdade social e econômica (tradução livre).
} 
produtivo (incluindo capital humano e não-humano) entre os cidadãos, o desestímulo da transmissão de vantagens entre gerações mediante a tributação de heranças e doações, com o fito de limitar desigualdades decorrentes da acumulação em termos de riqueza (propriedades) e, por fim, as os mecanismos de combate à corrupção da política democrática, tais como o financiamento público de partidos políticos e de campanhas eleitorais e a provisão pública de fóruns para debates políticos, necessárias para que se afastem os efeitos da influência excessiva de interesses financeiros de corporações na política.

A integração das três questões resulta em um sistema capacitado à ultrapassar as limitações do sistema econômico do bem-estar social, demonstrando a plena integração entre os princípios de justiça e o aspecto econômico da organização da sociedade.

No que tange ao princípio da liberdade igual (primeiro princípio de justiça) de John Rawls, sua relação com o sistema proposto da democracia de cidadãos proprietários é definida pela última das questões acima expostas, eis que a limitação dos efeitos da riqueza no processo político implicaria na proteção da participação cívica individual de cada cidadão, sem maiores interferências de poderes econômicos e financeiros "patrocinadores" de coligações e políticos.

No que concerne ao valor equitativo das oportunidades (primeira parte do segundo princípio de justiça), sua relação com a defesa da democracia de cidadãos-proprietários referese à capacidade de limitar a influência do contexto social sobre as oportunidades na vida dos indivíduos. Na prática, significa dizer que pessoas com o mesmo nível de talento e preparo, mas origens sociais distintas devem ter as mesmas oportunidades para alcançar o sucesso e cumprir seus planos de vida. Para tanto, o sistema da democracia de cidadãos-proprietários possui instituições que restringem a transmissão da riqueza mediante a tributação que impeça a transferência intergeracional de vantagens, sistemas públicos de saúde e educação, dentre outros (O’NEILL, 2009, p. 386).

Além disso, há o estímulo aos cidadãos proprietários em trabalharem visando de fato o produto de seu trabalho e não somente em salários, o que lhes garante mais autonomia para gerir o capital que utilizam no exercício diário de suas capacidades. É necessário apontar, ademais, que Rawls não admite a possibilidade de alguns membros da sociedade, estando aptos ao trabalho, deixarem de fazê-lo, pois a cooperação social é fundamental para que a democracia dos cidadãos proprietários funcione de forma justa e equitativa (ALARCON, 2017, p. 45). 
Por fim, a respeito do princípio da diferença de Rawls (situações de desigualdade na distribuição de bens primários sociais se justificam somente se elas trazem vantagens aos membros menos beneficiados da sociedade) e sua aplicação no sistema de democracia do cidadão proprietário, refere-se diretamente à luta contra uma desigualdade econômica e política tão severa, que acabaria gerando uma tirania de uma classe dominante quanto às outras que se sentiriam inferiores e agiriam com subserviência em razão de um status social inferior (O’NEILL, 2009, p. 383).

A desigualdade social é um dos fatores que pode ajudar entender as razões pelas quais as funções redistributivas do estado de bem estar social são insuficientes para retificar os danos de uma sociedade não igualitária, eis que esse atua de forma ex post (corringindo as desigualdades de renda e riqueza via redistribuição por meio de pagamentos e transferências aos mais pobres), ignorando os efeitos danosos que a própria desigualdade já causou ao autorrespeito de indivíduos de baixo status social, que podem levar a formas inaceitáveis de poder ou dominação.

O destinatário de pagamentos de bolsas ou outros instrumentos de transferência de renda pode passar a se ver como um beneficiário passivo, em vez de um indivíduo livre e igual com seu valioso plano de vida e de igual posição com seus concidadãos. Com o tempo, pode enxergar essas transferências como a fonte de seu status diminuído, e assim, como o mecanismo que mina seu autorrespeito. Exemplo claro da validade desta crítica de Rawls às correções ex-post de distorções sociais são os programas de transferência direta de renda, como o "bolsa família" no Brasil.

Pode-se pensar, de maneira plausível, que uma realização ex post "redistributiva" do princípio da diferença deixaria de abordar algumas das formas em que a desigualdade é ruim, pois se resumem àquelas que resultam da distribuição do próprio produto social ao invés de se preocuparem com as que resultam da forma como a produção social é organizada (O’NEILL, 2009, p. 384).

Destarte, somente um reordenamento anterior das relações sociais de produção parece ser capaz de permitir com que todos os graves danos de desigualdade sejam erradicados, pois desafiam a existência de posições de domínio econômico e político exacerbadas, que erodem o autorrespeito na sociedade.

A democracia de cidadãos-proprietários atua no sentido de promover o princípio da diferença, pois promove a dispersão da propriedade e o controle dos meios de produção, que 
geraria reciprocidade na sociedade e evitaria situações de controle social como esta apontada acima.

É interessante notar que, nesse ponto, Rawls compartilha da crença de John Stuart Mill, segundo a qual a existência de uma única opção real dos trabalhadores para com seus empregados (relação direta de emprego) diminui a liberdade e a independência individuais, afrouxa suas personalidades e imaginações, diminui o respeito mútuo entre as classes assalariadas e conduz à perda do autorrespeito entre os trabalhadores (ALARCON, 2017, p. 46).

Por conta de influência tão ruim deste tipo de relação de classe sobre a psicologia moral dos empregadores e empregados, Rawls procura alternativas de economia compartilhada, onde os trabalhadores detêm parte da propriedade e do capital privado, tais como cooperativas de trabalho, estímulos públicos em educação econômica para estimular os trabalhadores a se tornarem agentes econômicos independentes ou começarem seus próprios negócios (um exemplo no Brasil seria o Sistema S) e outras medidas intencionadas à dispersão da propriedade e do controle dos meios de produção.

Desta forma, as instituições de uma democracia proprietária devem ser capaz de superar problemas de dominação e desigualdade social, pois as instituições de um estado de bem-estar capitalista são estruturalmente incapazes de fazer (O’NEILL, 2009, p. 384).

Feitas essas observações sobre aplicabilidade prática dos princípios da justiça em um sistema econômico, fica mais claro que o argumento liberal igualitário de Rawls envolve uma reorganização socioeconômica radical, sendo esta a principal característica de uma democracia de cidadãos proprietários.

A ideia de políticas públicas de dispersão de capital visando a promoção direta do valor de igualdade por meio da redução ex ante de desigualdades sociais, políticas e econômicas implica em verdade na dispersão do poder através da dispersão da propriedade (aqui referida principalmente como a dos meios de produção, tal como a terra) e, por isso, seria o mecanismo ideal de combate à dominação social e perda do status de cidadão por parte dos indivíduos subordinados.

Portanto, a satisfação do princípio da diferença não se satisfaria materialmente somente com distribuições diretas de renda e riqueza, mas também sobre os bens sociais primários como a ocupação de cargos e posições de autoridade e responsabilidade e maior 
dispersão do controle sobre os recursos produtivos, para satisfação do autorrespeito necessário à condição de cidadão ativo em uma democracia (O’NEILL, 2009, p.385).

Assim sendo, resta demonstrado o porquê de políticas que visam a dispersão da propriedade e do controle sobre os meios de produção serem necessárias se quisermos criar uma sociedade justa. Um estado de bem estar social não persegue políticas semelhantes ao se preocupar principalmente com questões de redistribuição econômica ex post.

No entanto, é preciso ter em mente que é necessário cautela na observação de tal regime, posto que seu próprio idealizador deixou claro que se trata de um exercício hipotético. Basta observar o excesso de esquemas teóricos e tipologia econômica para enxergar que não se trata de um regime econômico possível de implementação total na realidade.

Mais importante do que isso, é perceber a possibilidade de absorver características dos sistemas econômicos propostos e misturá-los em uma amálgama de políticas possíveis. O próprio Rawls não é crítico de políticas de redistribuição indireta de renda e assistencialismo social que ocorrem no estado de bem estar social, tais como a previdência pública, as cotas sociais e os sistemas de saúde pública (O’NEILL, 2009, p. 390). Assim, adoção de elementos de uma democracia de cidadãos proprietários não precisa envolver a completa rejeição de mecanismos tradicionais do Estado de bem-estar.

Outra ponto importante é que não precisamos esperar uma total reorganização política e econômica como a democracia de cidadãos proprietários propõe, para colocar em prática mecanismos de combate à corrupção e diminuição da influência do poder financeiro sobre o poder político. Esperar um reordenamento igualitário das relações produtivas é demasiado ingênuo e desnecessário, sendo tal medida necessária inclusive em regimes baseados no estado de bem estar social tradicional.

Desta forma, é possível endossar os princípios de justiça fundados na concepção liberal igualitária de Rawls e mesmo algumas características do conjunto de políticas da proposta da democracia de cidadãos proprietários, com expectativa de que alguns objetivos (em termos de alcançar e garantir a justiça social) possam ser alcançados, mesmo com as restrições de um regime econômico de bem estar social tradicional, pois este é o sistema mais comum e difundido na realidade dos estados democráticos e sociais de direito ocidentais.

\section{CONSIDERAÇÕES FINAIS}


Na concepção de justiça como equidade de Rawls, a propriedade privada individual (com as exceções politicamente controversas relativas à propriedade dos meios de produção, recursos naturais e àquelas decorrentes de transmissão por herança) seria um direito fundamental e um bem primário, sendo parte da estrutura básica da sociedade.

No que tange à aplicação prática desta ideia (aspecto econômico e institucional), o direito de propriedade e sua relação com os princípios de justiça liberal igualitária propostos por Rawls, é reconhecido em um regime socioeconômico denominado democracia do cidadão proprietário, onde o autor propõe sua dispersão entre os indivíduos, visando evitar-se o controle político e econômico sobre a democracia.

Isso ocorreria de forma prévia e gradual, sendo uma proposta notoriamente teórica e especulativa, onde Rawls visa articular seus princípios de justiça com a realidade econômica e institucional da democracia, procurando afastar-se da ideia de que o estado capitalista com contornos de bem estar social seria suficiente para elidir desigualdades sociais e políticas, cuja origem está na base de sua própria formação.

As conexões entre os princípios e a estrutura básica da democracia de cidadãos proprietários são fortes e estão traçadas pela teoria política normativa contemporânea de Rawls. Mesmo diante de uma estrutura teórica a qual não corresponde a nada que saibamos ter sido ou ser praticado até o momento, não se pode negligenciar o tema, dado que se trata de uma resposta que invariavelmente procura um meio termo entre a igualdade e a liberdade.

Talvez um passo seguinte rumo ao aprofundamento do tema possa ser uma abordagem empírica a partir de contextos reais, feitas à luz da ideia de democracia de cidadãos-proprietários e de suas relações com os princípios rawlsianos de justiça, principalmente em países como o Brasil, onde direito de propriedade, suas consequências políticas, econômicas e sociais e a necessidade de readequá-las não é tema desconhecido ao público, posto que questão agrária é historicamente associada à desigualdade social, oriunda do nosso próprio processo colonizador. Joaquim Nabuco (2005, p. 59) já havia dito, no século XIX, que "[...] onde há grande número de pequenos proprietários a propriedade está muito mais firme e solidamente fundada do que onde por leis injustas ela é o privilégio de muito poucos.".

Uma abordagem como esta pode tanto elevar como acabar com qualquer possibilidade de prática da democracia de cidadãos proprietários, fundada na dispersão da propriedade em pequenos módulos rurais. Na pior das hipóteses, será um mecanismo capaz de 
revelar as desigualdades, a injustiça e a insuficiência dos instrumentos de distribuição de bens dos nossos sistemas socioeconômicos, em todos os seus planos.

\section{REFERÊNCIAS BIBLIOGRÁFICAS}

ALARCON, Sylvio. A DIMENSÃO ECONÔMICA DA JUSTIÇA IGUALITÁRIA: A DEMOCRACIA DE CIDADÃOS-PROPRIETÁRIOS NA TEORIA DA JUSTIÇA DE RAWLS. Cadernos De Ética E Filosofia Política, v. 2, n. 31, p. 30-48, 2017.

BRITO FILHO. José Cláudio Monteiro de. Ações Afirmativas. 3. ed. São Paulo: LTr, 2014.

GARGARELlA, Roberto. As teorias da justiça depois de Rawls. São Paulo: M. Fontes, 2008.

KYMLICKA, Will. Filosofia política contemporânea. Trad. Luís Carlos Borges, São Paulo: Martins Fontes, 2006

NABUCO, Joaquim. Campanha abolicionista no Recife: eleições 1884. Brasília: Senado Federal, Conselho Editorial, 2005.

O'NEILL, Martin. Liberty, equality and property- owning democracy. Journal of Social Philosophy, v. 40, n. 3, p. 379-396, 2009.

RAWLS, John. Justiça como equidade: uma reformulação. Trad. Claudia Berliner. São Paulo: Martins Fontes, 2003

RAWLS, John. Uma teoria da justiça. Tradução de Jussara Simões. São Paulo: Martins Fontes, 2008.

SÁ, João Daniel Macedo. Direito de Propriedade e Teoria da Justiça: a defesa da propriedade na justiça distributiva a partir da concepção de John Rawls. Sequência (Florianópolis), n. 82, p. 242-264, 2019.

WEBER, Thadeu. O direito de propriedade e justiça. REI-REVISTA ESTUDOS INSTITUCIONAIS, v. 2, n. 2, p. 799-817, 2016. 